\title{
The Influence of the Degree of Saturation of Crop Rotations with Alfalfa (Medicago Sativa L.) and Winter Wheat (Triticum Aestivum L.) with Ncp on the Accumulation of Plant Mass and Nutrients in the Energy Storage System of Soil Content in the Western Precaspian
}

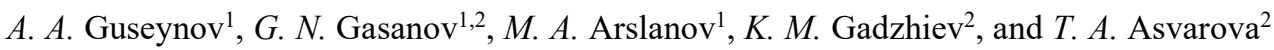 \\ ${ }^{1}$ Dagestan State Agrarian University named after M.M. Dzhambulatov, Makhachkala, Russia \\ ${ }^{2}$ Dagestan State Federal Research Center of the Russian Academy of Sciences, Makhachkala, Russia
}

\begin{abstract}
The energy storage system of soil maintenance in the irrigation landscapes of the Western Precaspian is based on the use of the second half of summer for the formation of a natural crop phytocenosis (NCP) and plowing it for green fertilizer. The article deals with the formation of plant mass in grain-grass crop rotations, the concentration and accumulation of nutrients in it. The degree of saturation of alfalfa (Medicago sativa L.) and winter wheat (Triticum aestivum L.) with natural crop phytocenosis (NCP) crop rotations ranges from 0 to $100 \%$. The most productive of the studied crop rotations is a four-field with one output field of alfalfa and three fields of winter wheat, after harvesting which in the second half of summer a $\mathrm{NCP}$ for green fertilizer is formed. In this crop rotation, $97.4 \mathrm{t}$ of agricultural products were produced on 1 ha of the crop rotation area, including $30.2 \mathrm{t} / \mathrm{ha}$ of its non-alienable part from the soil. Accordingly, the removal of $\mathrm{N}, \mathrm{P}_{2} \mathrm{O}_{5}$ and $\mathrm{K}_{2} \mathrm{O}$ from the soil increases. The proportion of the returned amount of nutrients from the phytomass inalienable from the soil was (\%): $\mathrm{N}-17.7 ; \mathrm{P}_{2} \mathrm{O}_{5}$ and 45.3 .
\end{abstract}

\section{Introduction}

In the southern regions of the country (the North Caucasus, the Lower Volga region), after harvesting winter grain crops, there are 100-120 days with a warm period of the year. The sum of positive air temperatures for this period is $2500-2600^{\circ} \mathrm{C}$, active temperatures above $10^{\circ} \mathrm{C}-2200-2300^{\circ} \mathrm{C}$, photosynthetically active radiation (FAR) - $20-22 \mathrm{kcal} / \mathrm{cm}^{2}$, or, respectively, $60-62 \% ; 55-60 \%$ and $33-37 \%$ of their annual amount. This period is currently used for tillage for the next crop according to various systems, the main purpose of which is the destruction of germinating weeds. At the same time, the above-mentioned climatic resources are irrevocably and without benefit for agricultural production. Researchers recommend using this period to provoke the germination of weeds (natural phytocenosis), and use the resulting mass for green fertilizer [1, 2]. According to [2, 4], this makes it possible to obtain more than $20 \mathrm{t} / \mathrm{ha}$ of aboveground and underground phytomass, and using 
it as a siderate increases the yield of winter wheat (Triticum aestivum) with repeated sowing by $15-17 \%$. It is even proposed to have a purely grain crop rotation, where every year the grain crop is sown according to the crop natural phytocenosis (NCP). [5, 6, 7] it is believed that NCP in the irrigation landscapes of the south of our country is a kind of busy steam, but in a different time interval (in the second half of summer) and on a different technological basis (not sown siderates, but NCP). In our opinion, the energy storage system of soil maintenance proposed by these authors should become the basis of agrotechnologies of organic agriculture in our country.

\section{Materials and Methods}

This article discusses the issues of accumulation of plant mass and nutrients in it in graingrass crop rotations with varying degrees of saturation with alfalfa (Medicago sativa) and winter wheat (Triticum aestivum) with NCP.

Table 1. Scheme of experience.

\begin{tabular}{|c|c|c|}
\hline \multirow{2}{*}{ Crop rotation } & \multicolumn{2}{|c|}{ Degree of saturation of crop rotation, \% } \\
\cline { 2 - 3 } & Alfalfa (Medicago sativa) & $\begin{array}{c}\text { winter wheat (Triticum } \\
\text { aestivum) with NCP }\end{array}$ \\
\hline 1 & 100 & 0 \\
\hline 2 & 75 & 25 \\
\hline 3 & 50 & 50 \\
\hline 4 & 25 -output field & 75 \\
\hline 5 & 0 & 100 \\
\hline
\end{tabular}

The plot area is $100 \mathrm{~m}^{2}$, the repetition is 4 times, crop rotations are 4 complete, the years of research 2013-2019.

The soil of the experimental site in "LLC Vimpel2002" of the Khasavyurt district of the Republic of Dagestan is light-chestnut, contains in the arable layer: humus $2.77 \%, \mathrm{P}_{2} \mathrm{O}_{5^{-}}$ $2.21, \mathrm{~K}_{2} \mathrm{O}-32.8 \mathrm{mg} / 100 \mathrm{~g}$ of soil, its density is $1.24 \mathrm{~g} / \mathrm{cm}^{3}$. The lowest moisture capacity of the $0-0.6 \mathrm{~m}$ layer is $29.2 \%$.

Agrochemical and agrophysical properties of the soil were determined according to existing methods $[8,9]$, observations, records, analysis of the crop structure were carried out according to $[10,11]$, statistical data processing was carried out according to [12]. Watering of the soil after harvesting winter wheat for the formation of NCP was carried out in the first decade of July, NCP harvesting - in the phase of onset of milk ripeness of seeds of dominant phytocenoses (late August - early September), sowing of winter wheat in the first decade of October (Grom variety) with a norm of 5 million. germinating seeds per 1 ha. Superphosphate was introduced under alfalfa: for plowing $\mathrm{P}_{40}$ for one year of using grass and $\mathrm{P}_{10}$ for sowing, nitrogen and potash fertilizers were not given. For winter wheat, $\mathrm{P}_{40}$ was applied for plowing, when sowing with seeds $\mathrm{P}_{10}$, for pre-sowing cultivation (harrowing) - $\mathrm{N}_{30}$, the same amount was added to the top dressing in the tillering phase in early spring. Potash fertilizers were not applied, given the high content of exchangeable potassium in the soil. Otherwise, the technology of cultivation of alfalfa and winter wheat corresponded to the zonal recommendations. Statistical processing of the results was carried out according to B.A. Dospekhov [12], the Microsoft Exsel computer program was also used. 


\section{Results and Discussion}

The degree of saturation of crop rotations with alfalfa (Medicago sativa), winter wheat (Triticum aestivum) with NCP and, especially, the accumulation of phytomass in the soil, inalienable from the soil, plays a crucial role in the accumulation of nutrients in the arable soil layer. In our studies, an increase in the share of the most productive crop - alfalfa - in the structure of sown areas to $100 \%$ did not lead to an increase in the phytomass accumulated by plants compared to other crop rotations, where winter wheat occupied part of the area with the subsequent formation of NCP (Table 2).

Table 2. Accumulation of plant mass in crop rotations with varying degrees of saturation with field crops, t/ha, 2014-2019.

\begin{tabular}{|c|c|c|c|c|c|c|c|}
\hline \multirow{2}{*}{$\begin{array}{l}\text { Crop rotation } \\
\text { and crop ratio, } \\
\%^{*}\end{array}$} & \multirow[t]{2}{*}{ Culture** } & Main & $\begin{array}{l}\text { Secondar } \\
\mathrm{y}\end{array}$ & $\begin{array}{l}\text { Crop } \\
\text { fields }\end{array}$ & Root & \multirow{2}{*}{$\begin{array}{l}\text { All } \\
\text { phytoma } \\
\text { ss }\end{array}$} & \multirow{2}{*}{$\begin{array}{l}\text { Including } \\
\text { not } \\
\text { alienated } \\
\text { from the } \\
\text { soil }\end{array}$} \\
\hline & & \multicolumn{2}{|c|}{ Products } & \multicolumn{2}{|c|}{ remains } & & \\
\hline \multirow{3}{*}{ 1. $100-0-0$} & 1 & 38,76 & 0 & 4,75 & 11,90 & \multirow{3}{*}{55,41} & \multirow{3}{*}{16,65} \\
\hline & 2 & 0 & 0 & 0 & 0 & & \\
\hline & 3 & 0 & 0 & 0 & 0 & & \\
\hline \multirow{3}{*}{$2.75-25-25$} & 1 & 36,63 & 0 & 3,25 & 9,35 & \multirow{3}{*}{67,76} & \multirow{3}{*}{18,23} \\
\hline & 2 & 5,57 & 4,32 & 1,66 & 3,63 & & \\
\hline & 3 & 0,51 & 0 & 0,12 & 0,20 & & \\
\hline \multirow{3}{*}{$3.50-50-50$} & 1 & 29,72 & 0 & 4,75 & 11,90 & \multirow{3}{*}{69,00} & \multirow{3}{*}{27,81} \\
\hline & 2 & 10,98 & 7,66 & 2,98 & 6,44 & & \\
\hline & 3 & 1,10 & 0 & 0,24 & 0,40 & & \\
\hline \multirow{3}{*}{$4.25-75-75$} & 1 & 38,7 & 0 & 0,87 & 11,90 & \multirow{3}{*}{97,37} & \multirow{3}{*}{30,17} \\
\hline & 2 & 16,50 & 12,00 & 4,65 & 10,08 & & \\
\hline & 3 & 1,71 & 0 & 0,36 & 0,60 & & \\
\hline \multirow{3}{*}{$5.0-100-100$} & 1 & 0 & 0 & 0 & 0 & \multirow{3}{*}{75,84} & \multirow{3}{*}{21,80} \\
\hline & 2 & 22,28 & 15,48 & 6,08 & 12,96 & & \\
\hline & 3 & 1,76 & 0 & 036 & 0,64 & & \\
\hline
\end{tabular}

*here and further in the tables: The ratio of alfalfa - winter wheat - NCP; **1- alfalfa (Medicago sativa L.), 2-winter wheat (Triticum aestivum L.), 3- NCP.

With the annual alternation of winter wheat with NCP, the production of phytomass on 1 ha of the crop area amounted to $75.84 \mathrm{t} / \mathrm{ha}$, or more than with alfalfa monoculture by $36.9 \%$. In the case when $25 \%$ of the area was allocated for grain crops with NCP (crop rotation 2), and alfalfa was used for three years, the amount of accumulated phytomass increased in relation to alfalfa monoculture by $22.3 \%$. There were two reasons for this: firstly, an increase in the yield of alfalfa from three years of use compared to four years by $0.51 \mathrm{t} / \mathrm{ha}(11.74 \mathrm{t} / \mathrm{ha}$ versus 11.23$)$, and secondly, additional production of $15.18 \mathrm{t} / \mathrm{ha}$ of winter wheat products with NCP.

The largest amount of phytomass per hectare of crop rotation area $-97.37 \mathrm{t} / \mathrm{ha}-\mathrm{was}$ obtained in the case of four-year use of alfalfa in the output field (25\% of the area) and the use of the rest of the area for growing winter wheat with its annual alternation with NCP for green fertilizer. The increase in the phytomass yield in relation to the alfalfa monoculture was $75.7 \%$. Respectively, crop rotations are $29.1 \%$ and $30.4 \%$ inferior to the best option, where both these groups of crops occupy $50 \%$ of the area and with $75 \%$ of alfalfa and $25 \%$ of winter wheat for grain, followed by the formation of NCP for green fertilizer (crop rotations 3 and 2). Alfalfa monoculture (No. 5) reduces the production of phytomass in relation to the best crop rotation with the alfalfa output field by $22.1 \%$. 
Important in this aspect is the question of the amount of plant mass remaining in the soil after harvesting, since only it is a reserve for increasing nutrients in the soil. In our studies, the maximum amount of products not alienated from the soil was obtained in the same crop rotations in which more than all plant products accumulated. First of all, this applies to the crop rotation with an output field of alfalfa and three fields of winter wheat with NCP for green fertilizer, where such a mass was obtained by $30.17 \mathrm{t} / \mathrm{ha}$, or more than with a monoculture of alfalfa by $81.2 \%$. The second position on this issue is occupied by crop rotation, where alfalfa and winter wheat with NCP occupy $50 \%$ each. The excess in relation to the monoculture of alfalfa in it is $37.1 \%$. Only $9.3 \%$ more plant mass, inalienable from the soil, accumulates compared to four-year cultivation of alfalfa in the same field in crop rotation with $75 \%$ of alfalfa and $25 \%$ of winter wheat.

The nitrogen concentration in the dry mass of alfalfa, winter wheat and NCP in our studies did not change significantly depending on the placement in crop rotations (Table 3 ). Most nitrogen was contained in hay and plant residues of alfalfa, NCP and winter wheat grain, phosphorus - in winter wheat grain and alfalfa roots, potassium - in the vegetative mass of alfalfa, NCP, in winter wheat grain and straw.

Table 3. Concentration of chemical elements in the plant mass of field crops, $\%$ of dry weight, 20142018

\begin{tabular}{|l|l|c|c|c|c|}
\hline $\begin{array}{l}\text { Nutritional } \\
\text { elements }\end{array}$ & \multicolumn{1}{|c|}{ Culture } & $\begin{array}{c}\text { Main } \\
\text { products }\end{array}$ & Straw & Crop residues & Roots \\
\hline \multirow{4}{*}{$\mathrm{N}$} & Alfalfa & $2.18 \pm 0,09$ & 0 & $2.11 \pm 0,09$ & $2.24 \pm 0,11$ \\
\cline { 2 - 7 } & winter wheat & $1.51 \pm 0,06$ & $0.66 \pm 0,03$ & $0.58 \pm 0,04$ & $0.41 \pm 0,03$ \\
\cline { 2 - 7 } & NCP & $1.70 \pm 0,08$ & 0 & $0.95 \pm 0,04$ & $0.51 \pm 0,05$ \\
\hline \multirow{3}{*}{$\mathrm{P}_{2} \mathrm{O}_{5}$} & Alfalfa & $0.59 \pm 0,04$ & 0 & $0.44 \pm 0,03$ & $0.62 \pm 0,07$ \\
\cline { 2 - 7 } & winter wheat & $0.77 \pm 0,07$ & $0.25 \pm 0,02$ & $0.22 \pm 0,02$ & $0.31 \pm 0,04$ \\
\cline { 2 - 7 } & NCP & $0.62 \pm 0,5$ & 0 & $0.38 \pm 0,02$ & $0.40 \pm 0,03$ \\
\hline \multirow{3}{*}{$\mathrm{K}_{2} \mathrm{O}$} & Alfalfa & $1.41 \pm 0,12$ & 0 & $0.93 \pm 0,04$ & $1.43 \pm 0,06$ \\
\cline { 2 - 7 } & winter wheat & $1.16 \pm 0,10$ & $1.00 \pm 0,07$ & $0.61 \pm 0,04$ & $0.70 \pm 0,05$ \\
\cline { 2 - 7 } & NCP & $1.22 \pm 0,10$ & 0 & $0.85 \pm 0,05$ & $0.61 \pm 0,05$ \\
\hline
\end{tabular}

Our studies on the accumulation of nitrogen in the harvest of various crop rotations have shown that the maximum amount of it is contained in the products obtained in crop rotations 2 (with $75 \%$ alfalfa and $25 \%$ winter wheat with NCP) and 4 (with the output field of perennial grass): 122.53 and $122.19 \mathrm{t} / \mathrm{ha}$, respectively (Table 4).

Table 4. $\mathrm{N}$ content in total and non-alienated plant mass in crop rotations with varying degrees of saturation with field crops, t/ha, 2014-2019.

\begin{tabular}{|c|c|c|c|c|c|c|c|}
\hline \multirow{2}{*}{$\begin{array}{l}\text { Crop rotation } \\
\text { and crop } \\
\text { ratio, } \% *\end{array}$} & \multirow[t]{2}{*}{$\begin{array}{c}\text { Culture* } \\
*\end{array}$} & Main & $\begin{array}{c}\text { Secondar } \\
\mathrm{y}\end{array}$ & $\begin{array}{l}\text { Crop } \\
\text { fields }\end{array}$ & Root & \multirow{2}{*}{$\begin{array}{c}\text { All } \\
\text { phytoma } \\
\text { ss }\end{array}$} & \multirow{2}{*}{$\begin{array}{c}\text { Including } \\
\text { not } \\
\text { alienated } \\
\text { from the } \\
\text { soil }\end{array}$} \\
\hline & & \multicolumn{2}{|c|}{ products } & \multicolumn{2}{|c|}{ remains } & & \\
\hline \multirow{3}{*}{ 1. $100-0-0$} & 1 & 84,50 & 0 & 4,75 & 6,34 & \multirow{3}{*}{95.59} & \multirow{3}{*}{11,09} \\
\hline & 2 & 0 & 0 & 0 & 0 & & \\
\hline & 3 & 0 & 0 & 0 & 0 & & \\
\hline \multirow{3}{*}{$2.75-25-25$} & 1 & 79,85 & 0 & 6,86 & 20,94 & \multirow{3}{*}{122,53} & \multirow{3}{*}{31,42} \\
\hline & 2 & 8,41 & 2,85 & 0,96 & 1,49 & & \\
\hline & 3 & 0,87 & 0 & 0,11 & 0,19 & & \\
\hline $3.50-50-50$ & 1 & 64,80 & 0 & 4,60 & 21,24 & 119,15 & 32.69 \\
\hline
\end{tabular}


Table 4. Continued

\begin{tabular}{|l|c|c|c|c|c|c|c|}
\hline & 2 & 16,60 & 5,06 & 1,73 & 2,64 & & \\
\cline { 2 - 6 } & 3 & 1,87 & 0 & 0,23 & 0,38 & & \\
\hline \multirow{3}{*}{$4.25-75-75$} & 1 & 17,79 & 0 & 4,75 & 6,34 & \multirow{3}{*}{122,19} & \multirow{2}{*}{21,66} \\
\cline { 2 - 6 } & 2 & 24,92 & 7,92 & 2,70 & 4,13 & \\
\cline { 2 - 6 } $5.0-100-100$ & 3 & 2,91 & 0 & 0,34 & 0,57 & & \\
& 1 & 0 & 0 & 0 & 0 & \multirow{3}{*}{56,80} & \multirow{2}{*}{12,76} \\
\cline { 2 - 6 } & 2 & 33,64 & 10,22 & 3,51 & 5,31 & & \\
\cline { 2 - 6 } & 3 & 2,99 & 0 & 0.34 & 0,61 & & \\
\hline
\end{tabular}

Crop rotation 3 is not much (by $2.8 \%$ ) inferior to them, with the same share of both groups of crops. It is characteristic that with alfalfa monoculture, the nitrogen content in the phytomass decreases by $28.2 \%$ compared to the best crop rotation in this respect. A feature of crop rotation 5 without alfalfa is the minimal accumulation of nitrogen in the phytomass obtained in it, which is inferior to one of the best crop rotations (fourth) by $40.6 \%$.

If we evaluate the studied crop rotations by the nitrogen content in phytomass that is not alienated from the soil, then crop rotation 3 has an indisputable advantage with the same proportion of the studied crop groups $-32.69 \mathrm{t} / \mathrm{ha}$. In comparison with it, in crop rotation 2 with $75 \%$ of alfalfa and $25 \%$ of winter wheat with NCP, the content of this element decreases by only $3.9 \%$, more significantly - by 33.7 and $61.0 \%$, respectively - it decreases in crop rotations 4 and 5 with the output field of alfalfa and the annual alternation of winter wheat with NCP. The minimum amount of nitrogen accumulates during alfalfa monoculture, it is possible that this is due to the removal of a large amount of this food element with the harvest of phytomass.

In the accumulation of $\mathrm{P}_{2} \mathrm{O}_{5}$ in the phytomass harvest in the studied crop rotations, a slightly different picture is observed: most phosphates accumulate in the phytomass of the third crop rotation with the same number of alfalfa and winter wheat fields with NCP $38.20 \mathrm{t} / \mathrm{ha}$ (Table 5), the second and third positions are occupied by crop rotation 2 with $75 \%$ alfalfa and $25 \%$ winter wheat with NCP and crop rotation 4 with an output field of alfalfa and three fields of wheat with NCP. Similar values were obtained in contrasting crop rotations: with a monoculture of alfalfa and annual alternation of winter wheat with NCP.

Table 5. The content of $\mathrm{P}_{2} \mathrm{O}_{5}$ in the total and non-alienated from the soil plant mass in crop rotations with varying degrees of saturation with field crops, $\mathrm{t} / \mathrm{ha}, 2014-2019$.

\begin{tabular}{|c|c|c|c|c|c|c|c|}
\hline \multirow{2}{*}{$\begin{array}{l}\text { Crop rotation } \\
\text { and crop } \\
\text { ratio, } \% *\end{array}$} & \multirow{2}{*}{$\underset{*}{\text { Culture* }}$} & Main & $\begin{array}{c}\text { Secondar } \\
\mathrm{y}\end{array}$ & $\begin{array}{l}\text { Crop } \\
\text { fields }\end{array}$ & Root & \multirow{2}{*}{$\begin{array}{l}\text { All } \\
\text { phytom } \\
\text { ass }\end{array}$} & \multirow{2}{*}{$\begin{array}{l}\text { Including not } \\
\text { alienated from } \\
\text { the soil }\end{array}$} \\
\hline & & \multicolumn{2}{|c|}{ products } & \multicolumn{2}{|c|}{ remains } & & \\
\hline \multirow{3}{*}{ 1. $100-0-0$} & 1 & 22,86 & 0 & 2,09 & 7,38 & \multirow{3}{*}{32,33} & \multirow{3}{*}{9,47} \\
\hline & 2 & 0 & 0 & 0 & 0 & & \\
\hline & 3 & 0 & 0 & 0 & 0 & & \\
\hline \multirow{3}{*}{$2.75-25-25$} & 1 & 21,61 & 0 & 1,43 & 5,88 & \multirow{3}{*}{35,41} & \multirow{3}{*}{79,43} \\
\hline & 2 & 4,29 & 1,08 & 0,36 & 1,12 & & \\
\hline & 3 & 0,52 & 0 & 0,04 & 0,08 & & \\
\hline \multirow{3}{*}{$3.50-50-50$} & 1 & 17,53 & 0 & 0,96 & 5,80 & \multirow{3}{*}{38,20} & \\
\hline & 2 & 8,40 & 1,92 & 0,66 & 2,00 & & \\
\hline & 3 & 0,68 & 0 & 0,09 & 0,16 & & \\
\hline \multirow{3}{*}{$4.25-75-75$} & 1 & 4,81 & 0 & 0,38 & 7,38 & \multirow{3}{*}{33,85} & \multirow{3}{*}{13,34} \\
\hline & 2 & 12,70 & 3,00 & 1,02 & 3,12 & & \\
\hline & 3 & 1,06 & 0 & 0,14 & 0,24 & & \\
\hline \multirow{3}{*}{$5.0-100-100$} & 1 & 0 & 0 & 0 & 0 & \multirow{3}{*}{33,00} & \multirow{3}{*}{21,80} \\
\hline & 2 & 22,28 & 3,87 & 1,34 & 4,02 & & \\
\hline & 3 & 1,09 & 0 & 0,14 & 0,26 & & \\
\hline
\end{tabular}


Alfalfa monoculture is not the best option for the accumulation of exchangeable potassium in the phytomass harvest (Table 6). In this regard, the most preferable is crop rotation 3 with an equal number of fields of perennial grass and winter wheat with NCP, the phytomass of which contained $85.57 \mathrm{t} / \mathrm{ha}$ of $\mathrm{K}_{2} \mathrm{O}$, its increase in relation to alfalfa monoculture in it was $13.2 \%$.

Table 6. $\mathrm{K}_{2} \mathrm{O}$ content in total and non-alienated plant mass in crop rotations with varying degrees of saturation with field crops, t/ha, 2014-2019.

\begin{tabular}{|c|c|c|c|c|c|c|c|}
\hline \multirow{2}{*}{$\begin{array}{l}\text { Crop rotation } \\
\text { and crop } \\
\text { ratio, } \% *\end{array}$} & \multirow{2}{*}{$\underset{*}{\text { Culture* }}$} & Main & $\begin{array}{c}\text { Secondar } \\
\mathrm{y}\end{array}$ & $\begin{array}{l}\text { Crop } \\
\text { fields }\end{array}$ & Root & \multirow{2}{*}{$\begin{array}{c}\text { All } \\
\text { phytoma } \\
\text { ss }\end{array}$} & \multirow{2}{*}{$\begin{array}{l}\text { Including } \\
\text { not } \\
\text { alienated } \\
\text { from the } \\
\text { soil }\end{array}$} \\
\hline & & \multicolumn{2}{|c|}{ products } & \multicolumn{2}{|c|}{ remains } & & \\
\hline \multirow{3}{*}{ 1. $100-0-0$} & 1 & 54,18 & 0 & 4,38 & 17,02 & \multirow{3}{*}{75,58} & \multirow{3}{*}{21,40} \\
\hline & 2 & 0 & 0 & 0 & 0 & & \\
\hline & 3 & 0 & 0 & 0 & 0 & & \\
\hline \multirow{3}{*}{$2.75-25-25$} & 1 & 51,24 & 0 & 3,02 & 13,37 & \multirow{3}{*}{82,80} & \multirow{3}{*}{20,78} \\
\hline & 2 & 6,46 & 4,32 & 1,01 & 2,54 & & \\
\hline & 3 & 0,62 & 0 & 0,10 & 0,12 & & \\
\hline \multirow{3}{*}{$3.50-50-50$} & 1 & 41,61 & 0 & 1,89 & 13,56 & \multirow{3}{*}{85,57} & \multirow{3}{*}{23,56} \\
\hline & 2 & 12,74 & 7,66 & 1,82 & 4,51 & & \\
\hline & 3 & 1,34 & 0 & 0,20 & 0,24 & & \\
\hline \multirow{3}{*}{$4.25-75-75$} & 1 & 11,42 & 0 & 2,03 & 17,02 & \multirow{3}{*}{67,96} & \multirow{3}{*}{31,72} \\
\hline & 2 & 19,14 & 12,00 & 2,84 & 7,06 & & \\
\hline & 3 & 2,09 & 0 & 0,31 & 0,37 & & \\
\hline \multirow{3}{*}{$5.0-100-100$} & 1 & 0 & 0 & 0 & 0 & \multirow{3}{*}{58,13} & \multirow{3}{*}{15,63} \\
\hline & 2 & 25,75 & 15,48 & 3,71 & 9,07 & & \\
\hline & 3 & 2,15 & 0 & 0,31 & 0,39 & & \\
\hline
\end{tabular}

A reduction in the share of winter wheat with $\mathrm{NCP}$ in this crop rotation to $25 \%$ (crop rotation 2) leads to a decrease in $\mathrm{K}_{2} \mathrm{O}$ content by $4.7 \%$, but remains higher than the alfalfa monoculture by $8.5 \%$. In crop rotations with alfalfa output field (No. 2) and in its complete absence (No. 5), the accumulation of exchangeable potassium decreased by 10.1 and $23.1 \%$, respectively.

Crop rotation with the alfalfa output field is also the best in this case for the accumulation of exchangeable potassium in products not alienated from the soil. On 1 ha of the crop rotation area, $31.72 \mathrm{t} / \mathrm{ha}$ of exchangeable potassium accumulates in the phytomass of this crop rotation, or 2.9 times more than with alfalfa monoculture. Similar indicators were obtained in the second crop rotation with $75 \%$ alfalfa and $25 \%$ winter wheat with $\mathrm{NCP}$, exceeding the monoculture of perennial grass by 2.8 times In the fifth crop rotation, where alfalfa was completely excluded from the structure of sown areas, the inalienable part of the product contained $15 \%$ more of this plant nutrition element than with the monoculture of alfalfa.

\section{Conclusions}

1. The development of an energy storage system for soil maintenance in irrigation landscapes of the Western Precaspian, based on the use of the second half of summer for the formation of NCP and plowing it for green fertilizer, is an effective way to increase plant mass per unit area. The most productive of the studied crop rotations is a four-field with one output field of alfalfa (Medicago sativa L.) and three fields of winter wheat (Triticum aestivum L.), after harvesting which in the second half of summer a NCP for 
green fertilizer is formed. In this crop rotation, 97.4 tons of agricultural products were produced on 1 ha of the crop rotation area, including 30.2 tons/ha of its non-alienable part from the soil.

2. The ratio of the products produced in crop rotations and the part of it that is not alienated from the soil is the widest (3.48:1) was in the crop rotation without alfalfa, the narrowest $(2.47: 1)$ - in the crop rotation with the same area of alfalfa and winter wheat with NCP. In other crop rotations, it ranges from 3.23:1 (with an output field of alfalfa) to 3.72:1 (with three fields of alfalfa and one field of winter wheat with NCP).

3. Crop rotations with three and two fields of alfalfa, respectively, with one and two fields of winter wheat with NCP, accumulate the largest amount of nitrogen in the plant mass not alienated from the soil $-31.42-32.69 \mathrm{t} / \mathrm{ha}$. The minimum indicator was obtained with a monoculture of alfalfa $-11.09 \mathrm{t} / \mathrm{ha}$, with constant alternation of winter wheat and $\mathrm{NCP}$, it increases by $15.1 \%$, in crop rotation with the output field of perennial grass - by $95.3 \%$.

4. In phytomass that is not alienated from the soil, the maximum amount of $\mathrm{P}_{2} \mathrm{O}_{5}$ accumulates in a crop rotation without alfalfa - 80t/ha, and the minimum amount - with a monoculture of alfalfa and three fields of its four crop rotation fields $-9.47-9.43 \mathrm{t} / \mathrm{ha}$. Phosphates accumulate $41-61 \%$ more in crop rotations with an output field of alfalfa and an equal amount ( $50 \%$ of the area) of it and grain crops with NCP.

5. Crop rotation with an output field of alfalfa and three fields of winter wheat with $\mathrm{NCP}$ provides the output of the maximum amount of $\mathrm{K}_{2} \mathrm{O}$ from 1 ha of the crop rotation area $-31.72 \mathrm{t}$. With the annual alternation of winter wheat with $\mathrm{NCP}$, its production decreases by $50.7 \%$, and with alfalfa monoculture and in crop rotation with $75 \%$ of this crop - by 32.5 and $34.5 \%$, in crop rotation with an equal number of studied crops - by $25.7 \%$.

\section{References}

1. Zh.N. Abdullaev, G.N. Gasanov, A.A. Beksultanov, Agrarian science, 3, 9-12 (2012)

2. I.T. Tamazaev, M.R. Musaev, G. N. Gasanov, Bulletin of the Russian Agricultural Science, 4, 44-47 (2018)

3. E.N. Pakina, G.N. Gasanov, T.A. Asvarova, K.M. Gadzhiev, R.R. Bashirov, Problems of agroindustrial complex development in the region, 4(44), 30-36 (2021)

4. E.N. Pakina, G.N. Gasanov, Res. On Crops, 21(2), 152-158 (2020)

5. E. N. Pakina, G. N. Gasanov, T. A. Asvarova, Agrochemistry, 6, 73-783 (2021)

6. E.N. Pakina, G.N. Gasanov, T.A. Asvarova, Fertility, 2(119), 42-45 (2021)

7. E.N. Pakina, Fertility, 5(116), 21-24 (2020)

8. Workshop on agrochemistry, $2^{\text {nd }}, 689$ (2001)

9. I.P. Vasiliev, A.M. Tulikov, G.I. Bazdyrev, Practicum on agriculture, 424 (2005)

10. M.A. Fedin, Methodology of the State Commission on variety testing of agricultural crops, 239 (1985)

11. Methodological guidelines for conducting field experiments with forage crops, 198 (1987)

12. B.A. Dospekhov, Methodology of field experience, 416 (1985) 